\title{
Positional changes of the mandibular condyle in unilateral sagittal split ramus osteotomy combined with intraoral vertical ramus osteotomy for asymmetric class III malocclusion
}

\author{
Jun Park, Ki-Eun Hong, Ji-Eon Yun, Eun-Sup Shin, Chul-Hoon Kim, Bok-Joo Kim, Jung-Han Kim \\ Department of Oral and Maxillofacial Surgery, College of Medicine, Dong-A University, Busan, Korea
}

\begin{abstract}
J Korean Assoc Oral Maxillofac Surg 2021;47:373-381)
Objectives: In the present study, the effects of sagittal split ramus osteotomy (SSRO) combined with intraoral vertical ramus osteotomy (IVRO) for the treatment of asymmetric mandible in class III malocclusion patients were assessed and the postoperative stability of the mandibular condyle and the symptoms of temporomandibular joint disorder (TMD) evaluated.

Materials and Methods: A total of 82 patients who underwent orthognathic surgery for the treatment of facial asymmetry or mandibular asymmetry at the Department of Oral and Maxillofacial Surgery, Dong-A University Hospital, from 2016 to 2021 were selected. The patients that underwent SSRO with IVRO were assigned to Group I $(n=8)$ and patients that received bilateral SSRO (BSSRO) to Group II ( $\mathrm{n}=10$, simple random sampling). Preoperative and postoperative three-dimensional computed tomography (CT) axial images obtained for each group were superimposed. The condylar position changes and degree of rotation on the superimposed images were measured, and the changes in condyle based on the amount of chin movement for each surgical method were statistically analyzed.

Results: Group I showed a greater amount of postoperative chin movement. For the amount of mediolateral condylar displacement on the deviated side, Groups I and II showed an average lateral displacement of $0.07 \mathrm{~mm}$ and $1.62 \mathrm{~mm}$, respectively, and statistically significantly correlated with the amount of chin movement $(P=0.004)$. Most of the TMD symptoms in Group I patients who underwent SSRO with IVRO showed improvement.

Conclusion: When a large amount of mandibular rotation is required to match the menton to the midline of the face, IVRO on the deviated side is considered a technique to prevent condylar torque. In the present study, worsening of TMD symptoms did not occur after orthognathic surgery in any of the 18 patients.
\end{abstract}

Key words: Orthognathic surgery, Facial asymmetry, Sagittal split ramus osteotomy, Intraoral vertical ramus osteotomy, Temporomandibular joint disorder [paper submitted 2021. 8. 18 / revised 2021. 9. 26 / accepted 2021. 10. 6]

\section{Introduction}

In orthognathic surgery, sagittal split ramus osteotomy (SSRO) and intraoral vertical ramus osteotomy (IVRO) are representative surgical methods for treating mandibular prognathism, retrognathism, and facial asymmetry. Each surgical procedure has advantages and disadvantages, and the selection of the technique depends on the skill and preference of

\section{Jung-Han Kim}

Department of Oral and Maxillofacial Surgery, College of Medicine, Dong-A University, 26 Daesingongwon-ro, Seo-gu, Busan 49201, Korea

TEL: +82-51-240-5475

E-mail:omfsjhkim@dau.ac.kr

ORCID: https://orcid.org/0000-0002-3469-6136

(c) This is an open-access article distributed under the terms of the Creative Commons Attribution Non-Commercial License (http://creativecommons.org/ licenses/by-nc/4.0/), which permits unrestricted non-commercial use, distribution, and reproduction in any medium, provided the original work is properly cited.

Copyright (C) 2021 The Korean Association of Oral and Maxillofacial Surgeons. the operator and the preoperative condition of the patient's jawbone and temporomandibular joint ${ }^{1,2}$.

SSRO was first proposed by Trauner and Obwegerser ${ }^{3}$. After various modifications, the method was developed into the current surgical design and rigid fixation using plates and screws or bicortical screws ${ }^{3,4}$. The advantages of this procedure include the positioning of the distal segment of the mandible is facilitated, bone healing is promoted by allowing overlap of wide bony surfaces, and early function after surgery is enabled by using rigid fixation of the bone fragment $^{5,6}$. Caldwell and Letterman compared IVRO to SSRO ${ }^{7}$ and found IVRO was relatively easier with a lower risk of damage to the inferior alveolar nerve and blood vessels ${ }^{2}$. Because fixation is not required between the segments, condylar positioning is simplified. In previous studies, the mandibular condyle is reportedly repositioned to a physiologically equilibrated position during the postoperative physical therapy 
period, showing a therapeutic effect in most patients with temporomandibular joint disorder (TMD) $)^{8,9}$.

Bilateral SSRO (BSSRO) is the most often-used surgical procedure due to its advantages and good postoperative results $^{1,2}$. However, during surgery for mandibular asymmetry, BSSRO can create bony interference between the proximal and distal segments on the deviated side when the mandibular midline shift occurs to the opposite side, leading to condylar displacement from the mandibular fossa that may inadvertently change the lateral shape of the face and cause $\mathrm{TMD}^{1,10,11}$.(Fig. 1) Therefore, surgeons have devised various surgical methods to eliminate bony interference ${ }^{1}$. Among the various surgical methods, IVRO on the deviated side that generates condylar torque and SSRO on the opposite side should be considered an alternative surgical method to solve this problem ${ }^{12}$.

In the present study, the effects of SSRO combined with IVRO for the treatment of asymmetric mandible in class III malocclusion patients were assessed and the postoperative stability of the mandibular condyle and TMD symptoms evaluated.

\section{Materials and Methods}

\section{Patient selection}

A total of 82 patients who met both inclusion and exclusion criteria were selected among patients who underwent orthognathic surgery for facial asymmetry or mandibular asymmetry at Dong-A University Hospital between 2016 and 2021.

Inclusion criteria:

1) Patients were over 18 years of age and had achieved complete skeletal growth.
2) Patients with facial asymmetry with occlusal canting or chin deviation due to asymmetric growth of the mandibular ramus.

3) Chin deviation $3 \mathrm{~mm}$ or more based on the face midline.

4) Receiving three-dimensional (3D) computed tomography (CT) scan of face within 1 month before and after surgery.

5) Patients with preoperative and postoperative TMD symptoms and progress recorded in medical records.

Exclusion criteria:

1) Patients who underwent bilateral IVRO.

2) Patients who had a congenital anomaly of the mandibular condyle and the change in the position of the condyle cannot be properly detected.

3) Among the patients who underwent BSSRO, those who additionally underwent distal segment posterior bending osteotomy (DSPBO).

The study participants were classified as follows:

Group I: Patients who underwent IVRO on the deviated side and SSRO on the non-deviated side $(\mathrm{n}=8)$.

Group II: Patients who underwent BSSRO with the bony interference grinding method $(\mathrm{n}=10)$.

Only eight people were assigned to Group I and not randomly selected. In Group II, 10 of 74 patients were randomly selected and served as a control group to evaluate the effectiveness of SSRO combined with IVRO.

\section{Surgical method selection}

The most important criterion for deciding between BSSRO and SSRO with IVRO is the presence of facial asymmetry. In particular, in the case of facial asymmetry accompanied by mandibular deviation, canting is eliminated for improved results. Furthermore, when the mandible is positioned in the
A

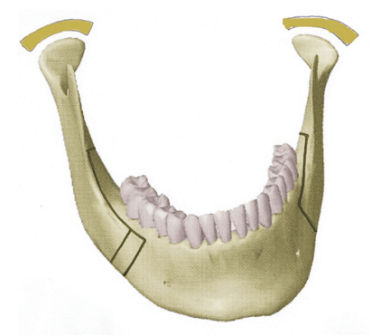

B

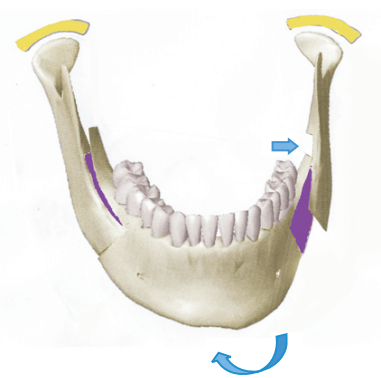

C

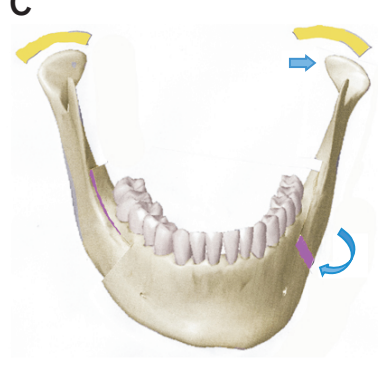

Fig. 1. Changes in the position of the deviated side condyle during osteotomy and fixation in bilateral sagittal split ramus osteotomy (BSSRO). A. Asymmetric mandible before osteotomy (left deviation). B. Mandible after osteotomy (reposition of the mandible on the midline of the face). C. Lateral displacement in the left condyle after fixation. During fixation of the left proximal segment to the distal segment, the condyle was displaced laterally due to bony interference.

Jun Park et al: Positional changes of the mandibular condyle in unilateral sagittal split ramus osteotomy combined with intraoral vertical ramus osteotomy for asymmetric class III malocclusion. J Korean Assoc Oral Maxillofac Surg 2021 
middle, condylar torque is generated in the proximal segment on the deviated side. Therefore, SSRO combined with IVRO is considered the surgical method of choice to prevent condylar torque in patients with severe mandibular deviation. However, if the distal segment of the mandible moves forward after surgery, BSSRO with grinding is performed because osseous nonunion may occur due to the loss of contact between the segments during IVRO. We performed 3D model surgery to determine the presence and amount of bony interferences during distal segment movement. Surgical treatment objective (STO) was identified and used as a criterion for deciding when to perform IVRO. During surgical decision-making, we also focused on the presence of TMD symptoms on the deviated side. In the presence of TMD symptoms on the deviated side, the possibility of IVRO was evaluated.

\section{3D CT image acquisition and superimposition}

Preoperative and postoperative 3D CT data (digital imaging and communications in medicine [DICOM]) were obtained from the patients and the best image was selected to identify the front, rear, and lateral position changes, and condylar rotation. Adobe Photoshop CS3 was used to read the DICOM file and superimpose the preoperative and postoperative 3D images. Both sides of the mastoid process (temporal bone) bone shape pattern, the posterior midpoint of foramen magnum, and zygomatic arch were anatomical landmarks for CT image superimposition.(Fig. 2)

\section{Condylar position change evaluation}

The $\mathrm{x}$ - and y-axes were formed on the superimposed CT image and changes in condylar position were observed by placing three points on the center, inner, and outer parts of the condyle. Mandibular rotation and bodily movement were measured.(Fig. 3) For anteroposterior displacement, a positive value was defined as anterior displacement and a negative value as posterior displacement. For mediolateral displacement, a positive value was defined as lateral displacement and a negative value as medial displacement. For angle measurements, a positive angle was defined as inward rotation and a negative angle as outward rotation. Based on this,
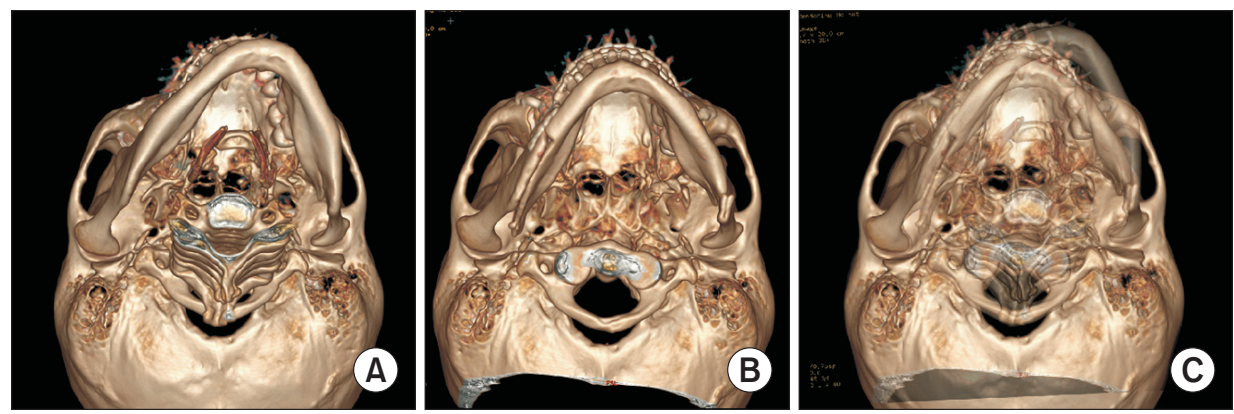

Fig. 2. Three-dimensional (3D) computed tomography (CT) image superimposition for measuring condyle position change. A. Preoperative 3D CT image. B. Postoperative 3D CT image. C. Preoperative and postoperative image superimposition. The images were superimposed using important anatomical structures as landmarks.

Jun Park et al: Positional changes of the mandibular condyle in unilateral sagittal split ramus osteotomy combined with intraoral vertical ramus osteotomy for asymmetric class III malocclusion. J Korean Assoc Oral Maxillofac Surg 2021

Rt. Condyle axial image

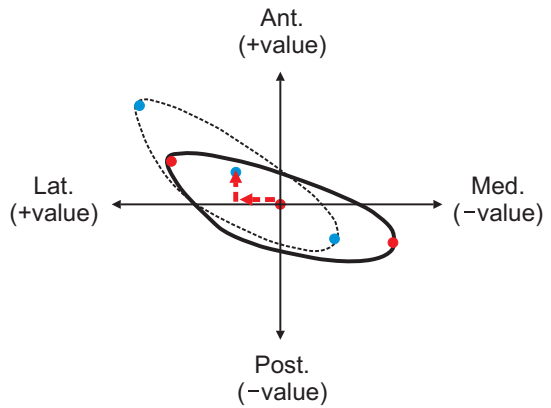

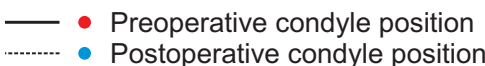

Ant.

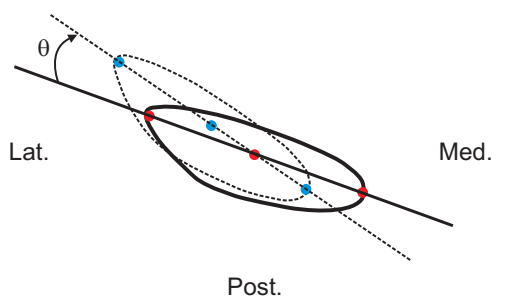

Inward rotation: +value $\theta$

( Outward rotation: - value $\theta$
Fig. 3. Measurement of condyle position change. A. Mediolateral and anteroposterior displacement. B. Condyle rotation. (Rt.: right, Ant.: anterior, Lat.: lateral, Post.: posterior, Med.: medial) Jun Park et al: Positional changes of the mandibular condyle in unilateral sagittal split ramus osteotomy combined with intraoral vertical ramus osteotomy for asymmetric class III malocclusion. J Korean Assoc Oral Maxillofac Surg 2021 
three values were measured in both the deviated and nondeviated side condyles on the superimposed images, and the relationship between the three values and the amount of chin movement during surgery was statistically analyzed.

\section{TMD symptom evaluation}

Preoperative and postoperative medical records were used to evaluate the deterioration and incidence of preoperative and postoperative TMD symptoms. TMD symptoms were limited to joint disc displacement and masticatory muscle pain that did not significantly affect the results of orthognathic surgery. TMD, which may affect other surgical outcomes, was stabilized through treatment before orthognathic surgery.

One month before orthognathic surgery, the patient was examined for the presence of TMD symptoms. After surgery, the patient was re-evaluated for the decrease, disappearance, or development of new TMD symptoms based on the surgical method. In particular, the records were examined at more than 3 months after surgery to differentiate between temporary restricted mouth opening and masticatory muscle pain caused by surgical damage and intermaxillary fixation after surgery.

\section{Statistical analysis}

The data are presented as frequency and percentage for categorical variables and mean \pm standard deviation $(\mathrm{SD}) /$ median (interquartile range [IQR]) for numeric variables. Differences in study participant characteristics were compared across subgroups using the independent t-test or Mann-Whitney $\mathrm{U}$ test for continuous variables.

The differences in study participant characteristics were compared across subgroups using the ANOVA with Scheffé post-hoc test or the Kruskal-Wallis test with Dunn's post-hoc test. To determine the normal distribution of data, ShapiroWilk test was used. For graphical visualization, error bar charts and scatterplots were presented.

All statistical analyses were performed using IBM SPSS Statistics (ver. 26.0; IBM, Armonk, NY, USA) and $P<0.05$ were considered statistically significant.

\section{Results}

Changes in condylar position were measured in three aspects in Group I and Group II. Table 1 shows the results of

Table 1. Results of statistical analysis between chin movement and condylar position changes in the groups

\begin{tabular}{|c|c|c|c|}
\hline Variable & Group I & Group II & $P$-value \\
\hline \multicolumn{4}{|c|}{ Chin movement (mm) } \\
\hline Mean \pm SD & $8.63 \pm 4.27$ & $6.15 \pm 2.75$ & \multirow[t]{2}{*}{$0.155^{1}$} \\
\hline Median (IQR) & $7.25(5.25$ to 13.63$)$ & $5.75(3.75$ to 8.50$)$ & \\
\hline \multicolumn{4}{|c|}{ Mediolateral displacement } \\
\hline \multicolumn{4}{|c|}{ Deviated side (mm) } \\
\hline Mean \pm SD & $0.07 \pm 0.97$ & $1.62 \pm 0.98$ & \multirow[t]{2}{*}{$0.004^{1}$} \\
\hline Median (IQR) & $0.41(-0.93$ to 0.84$)$ & $1.48(0.89$ to 2.26$)$ & \\
\hline \multicolumn{4}{|c|}{ Non-deviated side (mm) } \\
\hline Mean \pm SD & $0.17 \pm 1.71$ & $1.13 \pm 0.90$ & \multirow[t]{2}{*}{$0.144^{1}$} \\
\hline Median (IQR) & $0.49(-1.79$ to 1.76$)$ & $1.18(0.65$ to 1.90$)$ & \\
\hline \multicolumn{4}{|c|}{ Anteroposterior displacement } \\
\hline \multicolumn{4}{|c|}{ Deviated side $(\mathrm{mm})$} \\
\hline Mean \pm SD & $0.87 \pm 1.44$ & $0.66 \pm 0.90$ & \multirow[t]{2}{*}{$0.700^{1}$} \\
\hline Median (IQR) & $1.36(-0.80$ to 2.09$)$ & 0.77 (0.09 to 1.18$)$ & \\
\hline \multicolumn{4}{|c|}{ Non-deviated side (mm) } \\
\hline Mean \pm SD & $-0.30 \pm 0.97$ & $0.27 \pm 0.82$ & \multirow[t]{2}{*}{$0.199^{1}$} \\
\hline Median (IQR) & $-0.06(-1.40$ to 0.54$)$ & $0.04(-0.27$ to 0.96$)$ & \\
\hline \multicolumn{4}{|l|}{ Condyle rotation } \\
\hline \multicolumn{4}{|l|}{ Deviated side $\left(^{\circ}\right)$} \\
\hline Mean \pm SD & $-7.11 \pm 6.87$ & $6.45 \pm 3.78$ & \multirow[t]{2}{*}{$0.000^{1}$} \\
\hline Median (IQR) & $-6.00(-13.55$ to -2.00$)$ & $5.80(3.40$ to 8.93$)$ & \\
\hline \multicolumn{4}{|c|}{ Non-deviated side $\left(^{\circ}\right)$} \\
\hline Mean \pm SD & $1.45 \pm 3.99$ & $3.90 \pm 3.83$ & \multirow[t]{2}{*}{$0.204^{1}$} \\
\hline Median (IQR) & $1.30(-2.70$ to 4.68$)$ & $4.35(0.78$ to 7.13$)$ & \\
\hline
\end{tabular}

(Group I: patients who underwent intraoral vertical ramus osteotomy on the deviated side and sagittal split ramus osteotomy [SSRO] on the non-deviated side, Group II: patients who underwent bilateral SSRO with the bony interference grinding method, SD: standard deviation, IQR: interquartile range, + value: anterior, lateral displacement, inward rotation, - value: posterior, medial displacement, outward rotation)

Shapiro-Wilk test was used to evaluate normality assumption.

${ }^{1} P$-values derived from independent $t$-test.

Jun Park et al: Positional changes of the mandibular condyle in unilateral sagittal split ramus osteotomy combined with intraoral vertical ramus osteotomy for asymmetric class III malocclusion. J Korean Assoc Oral Maxillofac Surg 2021 
the statistical analysis of chin movement and condylar position change.

\section{Chin movement}

Chin movement was defined as the amount of movement of the mandibular midline (menton) in the coronal plane after surgery, and additional movement caused by genioplasty was excluded. Although statistical significance was not observed, postoperative chin movement tended to be greater in Group I as shown in Table 1 and Fig. 4. The mandibles moved an average of $8.63 \pm 4.27 \mathrm{~mm}$ and $6.15 \pm 2.75 \mathrm{~mm}$ in Groups I and II, respectively.

\section{Mediolateral displacement}

\section{(+value: lateral movement/-value: medial movement)}

The mediolateral displacement on the deviated side condyle was $0.07 \pm 0.97 \mathrm{~mm}$ in Group I and $1.62 \pm 0.98 \mathrm{~mm}$ in Group II and was statistically significantly correlated with chin movement $(P=0.004)$.

The non-deviated side condyle measured $0.17 \pm 1.71 \mathrm{~mm}$ and $1.13 \pm 0.90 \mathrm{~mm}$ in Groups I and II, respectively, which were similar values to the deviated side but statistically nonsignificant $(P=0.144)$.

\section{Anteroposterior displacement}

(+value: anterior movement/-value: posterior movement)

The anteroposterior displacement of the deviated side condyle was $0.87 \pm 1.44 \mathrm{~mm}$ in Group I and $0.66 \pm 0.90 \mathrm{~mm}$ in Group II but was not statistically significantly correlated with chin movement $(P=0.700)$.

The non-deviated side condyle displacement was $-0.30 \pm 0.97 \mathrm{~mm}$ in Group I and $0.27 \pm 0.82 \mathrm{~mm}$ in Group II. The correlation with chin movement was statistically nonsignificant $(P=0.199)$.

\section{Condyle rotation \\ (+value: inward rotation/-value: outward rotation)}

The rotation of the deviated side condyle was $-7.11^{\circ} \pm 6.87^{\circ}$ in Group I and $6.45^{\circ} \pm 3.78^{\circ}$ in Group II and was statistically significantly correlated with chin movement $(P=0.000)$.
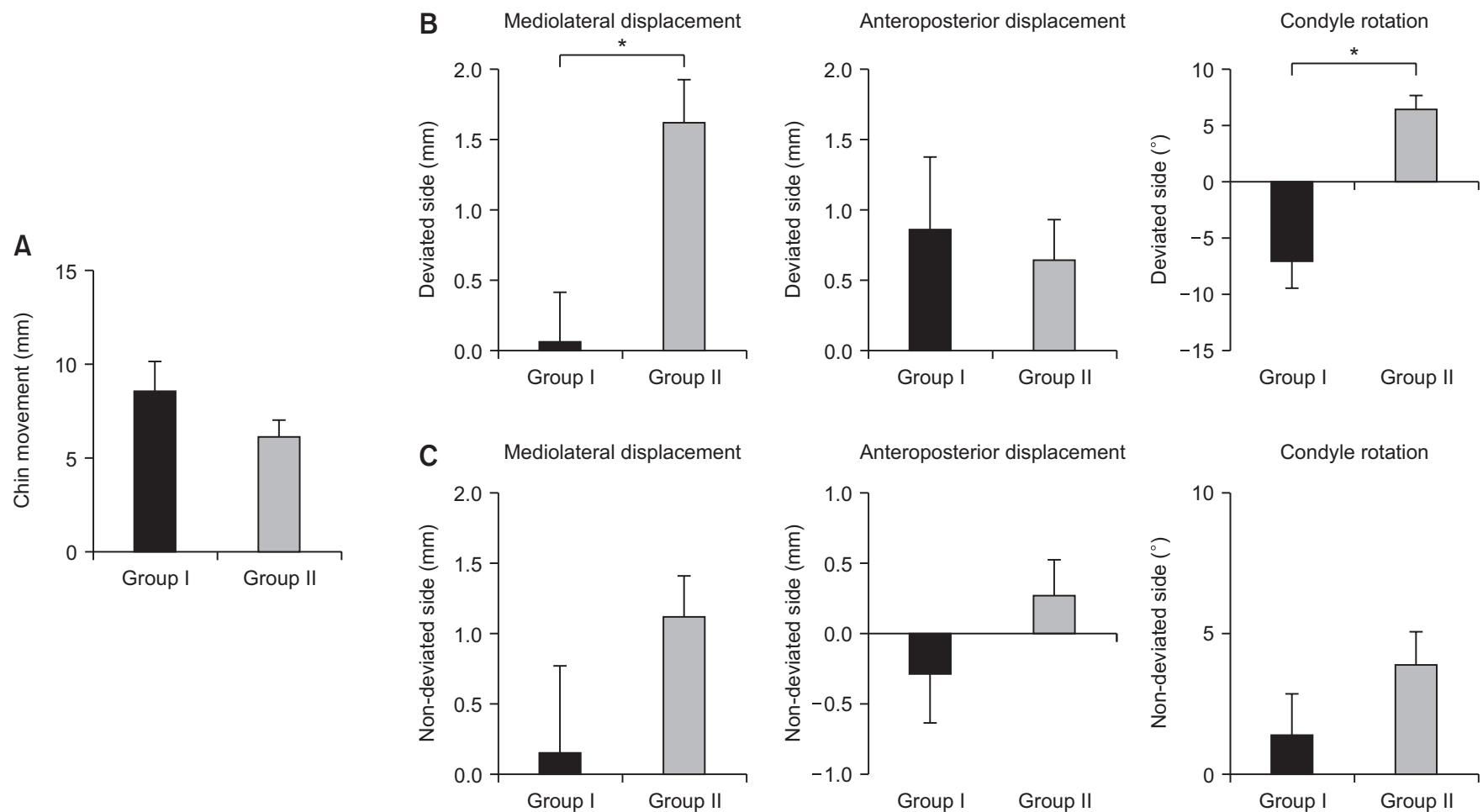

Fig. 4. Result of condyle position change between the two groups. A. Chin movement after surgery. B. Amount of displacement and rotation of the condyles on deviated side. C. Amount of displacement and rotation of the condyles on non-deviated side. ${ }^{*} P<0.05$. (Group I: patients who underwent intraoral vertical ramus osteotomy [IVRO] on the deviated side and sagittal split ramus osteotomy [SSRO] on the non-deviated side, Group II: patients who underwent bilateral SSRO with the bony interference grinding method)

Jun Park et al: Positional changes of the mandibular condyle in unilateral sagittal split ramus osteotomy combined with intraoral vertical ramus osteotomy for asymmetric class III malocclusion. J Korean Assoc Oral Maxillofac Surg 2021 
Table 2. Preoperative and postoperative temporomandibular joint disorder (TMD) symptoms

\begin{tabular}{|c|c|c|c|c|}
\hline & \multicolumn{2}{|c|}{ Group I ( $\mathrm{n}=8)$} & \multicolumn{2}{|c|}{ Group II $(n=10)$} \\
\hline & Preoperative & Postoperative & Preoperative & Postoperative \\
\hline \multicolumn{5}{|l|}{ TMD symptom } \\
\hline No symptoms & $1(12.5)$ & $5(62.5)$ & $3(30.0)$ & $5(50.0)$ \\
\hline TMD pain & $1(12.5)$ & $0(0)$ & $1(10.0)$ & $0(0)$ \\
\hline TMD noise & $1(12.5)$ & $3(37.5)$ & $4(40.0)$ & $5(50.0)$ \\
\hline LOM & $0(0)$ & $0(0)$ & $0(0)$ & $0(0)$ \\
\hline Myalgia & $1(12.5)$ & $0(0)$ & $0(0)$ & $0(0)$ \\
\hline TMD pain+noise & $3(37.5)$ & $0(0)$ & $2(20.0)$ & $0(0)$ \\
\hline TMD pain+LOM & $0(0)$ & $0(0)$ & $0(0)$ & $0(0)$ \\
\hline TMD pain+noise+LOM & $1(12.5)$ & $0(0)$ & $0(0)$ & $0(0)$ \\
\hline \multicolumn{5}{|l|}{ Result } \\
\hline Improved & \multicolumn{2}{|c|}{$7(87.5)$} & \multicolumn{2}{|c|}{$4(40.0)$} \\
\hline Deteriorated & \multicolumn{2}{|c|}{$0(0)$} & \multicolumn{2}{|c|}{$0(0)$} \\
\hline No change & \multicolumn{2}{|c|}{$1(12.5)$} & \multicolumn{2}{|c|}{$6(60.0)$} \\
\hline
\end{tabular}

(Group I: patients who underwent intraoral vertical ramus osteotomy on the deviated side and sagittal split ramus osteotomy [SSRO] on the nondeviated side, Group II: patients who underwent bilateral SSRO with the bony interference grinding method, LOM: limit of mouth opening) Values are presented as number $(\%)$.

Jun Park et al: Positional changes of the mandibular condyle in unilateral sagittal split ramus osteotomy combined with intraoral vertical ramus osteotomy for asymmetric class III malocclusion. J Korean Assoc Oral Maxillofac Surg 2021

The rotation of the condyle on the non-deviated side was $1.45^{\circ} \pm 3.99^{\circ}$ in Group I and $3.90^{\circ} \pm 3.83^{\circ}$ in Group II but was not statistically significantly correlated with chin movement ( $P=0.204)$.

\section{Preoperative and postoperative TMD symptoms}

Table 2 shows the changes in TMD symptoms before and after orthognathic surgery. Most of the TMD symptoms in Group I patients who underwent SSRO with IVRO showed improvement. Group II patients, who underwent BSSRO, showed similar improvement in TMD symptoms. Newly developed TMD symptoms did not occur in any of the patients.

\section{Discussion}

Among the complications that may appear after orthognathic surgery, TMD is reportedly the second most frequent occurrence after inferior alveolar nerve injury ${ }^{13}$. Various symptoms such as resorption of condyle, development of arthralgia, and masticatory muscle pain can occur ${ }^{13,14}$. Various opinions exist on postoperative TMD associated with orthognathic surgery. Some authors argue the incidence of TMD is high in skeletal symmetry and malocclusion before surgery, and the TMD symptoms can improve after orthognathic surgery $^{10,11,15,16}$. However, positional changes of the condyle may occur from the articular fossa during orthognathic surgery and excessive changes beyond the physiological limit may affect the masticatory muscles and the joint disc ${ }^{17}$. Therefore, surgeons are attempting to minimize condylar torque and positional change due to the movement of the mandible ${ }^{1}$ and several methods have been introduced to address this concern. The following four main methods are used: bony interference grinding, plate bending, BSSRO with DSPBO, and SSRO with IVRO ${ }^{1,12}$.(Fig. 5)

Bony interferences are eliminated by grinding to achieve passive contact between the proximal and distal segments. If a large interference is present, it cannot be completely eliminated, and there is an increased risk of trauma to the inferior alveolar nerve, blood vessels, and surrounding soft tissues during grinding ${ }^{1}$. Plate bending allows a gap at the end of the fracture section instead of rotation of the proximal segment to achieve contact between the proximal and distal segments and minimizes condylar torque during the fixation. However, malunion and nonunion (due to the lack of interface contact) and iatrogenic facial asymmetry in facial width are possible ${ }^{1,18,19}$. BSSRO with DSPBO eliminates bony interference with additional osteotomy of the most posterior part of the distal segment on the side that causes condylar torque and displacement during fixation of the proximal segment. This method has disadvantages such as difficult access during secondary osteotomy, considerable risk of damage to the inferior alveolar nerve, and worsening of postoperative patient discomfort ${ }^{1,20,21}$.

Because IVRO does not use rigid fixation, SSRO with IVRO causes less rotational displacement of the proximal segment on the deviated side and displaced or rotated condyles may return to their original physiologic position. Consequently, the additional effect of improved TMD symptoms can be obtained ${ }^{2}$. Therefore, SSRO combined with IVRO 

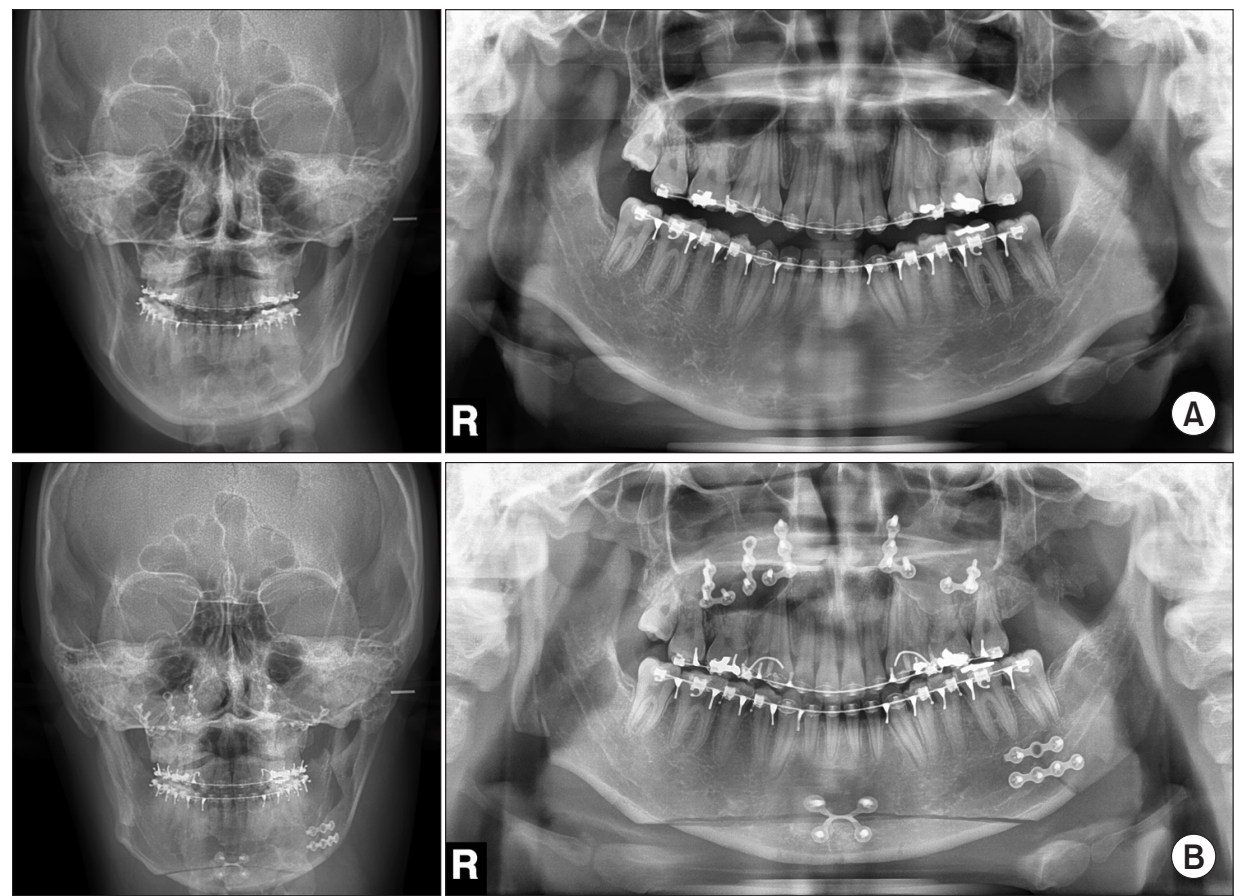

Fig. 5. Digital panoramic and cephalometric radiograph of sagittal split ramus osteotomy (SSRO) with intraoral vertical ramus osteotomy (IVRO). A. Preoperative radiography. B. Postoperative radiography (right SSRO/left IVRO). Jun Park et al: Positional changes of the mandibular condyle in unilateral sagittal split ramus osteotomy combined with intraoral vertical ramus osteotomy for asymmetric class III malocclusion. J Korean Assoc Oral Maxillofac Surg 2021
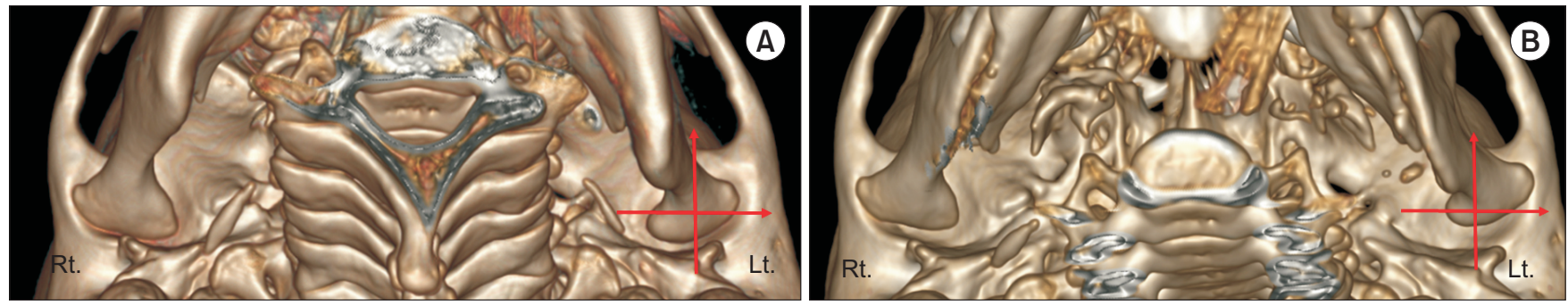

Fig. 6. Bilateral sagittal split ramus osteotomy (BSSRO) with bony interference grinding in a patient with asymmetric mandible (deviated side: left). A. Preoperative three-dimensional (3D) computed tomography (CT) image. B. Postoperative 3D CT image. Condylar displacement from the mandibular fossa is clearly observed on deviated side (left). (Rt.: right, Lt.: left)

Jun Park et al: Positional changes of the mandibular condyle in unilateral sagittal split ramus osteotomy combined with intraoral vertical ramus osteotomy for asymmetric class III malocclusion. J Korean Assoc Oral Maxillofac Surg 2021

is used as a surgical alternative to solve the spatial problem caused by BSSRO in cases of severe mandibular rotation and asymmetry ${ }^{11}$.

Among the methods described above, grinding bony interferences to minimize condylar torque in BSSRO is usually considered the first-line option ${ }^{22}$. However, bone grinding provides limited gains in the presence of large bony interferences or poor access due to the anatomical location ${ }^{1}$.(Fig. 6) Therefore, IVRO on the deviated side that generates condylar torque and SSRO on the opposite side as an alternative surgical method should be considered to solve this problem ${ }^{11}$. In the present study, the practical value of SSRO combined with IVRO as a surgical technique was evaluated based on changes in condylar position and TMD symptoms after surgery in 18 patients who underwent orthognathic surgery.
The amount of chin movement in Group I was higher than in Group II, indicating IVRO was more often used to minimize condylar torque on the deviated side condyle in patients with severe chin deviation. When determining the surgical approach, the decision to use IVRO with SSRO depends on the distance from menton to the midline of the face. Thus, when predicting the amount of bony interference on the deviated side during surgical preparation, grinding alone is insufficient to minimize torque generation in cases of severe menton deviation. Furthermore, for persistent TMD symptoms on the deviated side, IVRO is preferred. However, if IVRO is unsuitable for the facial contours, SSRO should be considered for the deviated side with additional DSPBO on the distal segment.

After measuring the change in condylar position between 
groups, the mediolateral displacement and rotation of the deviated side condyle were statistically significantly correlated with chin movement ( $P=0.004$ and $P=0.000$, respectively). For mediolateral displacement of the deviated side condyle, Group I $(0.07 \pm 0.97 \mathrm{~mm})$ condyles treated with IVRO showed minimal movement, and Group II $(1.62 \pm 0.98 \mathrm{~mm})$ condyles showed significant lateral displacement.(Fig. 4) IVRO prevented the lateral movement of the condyle. Conversely, in the case of SSRO with bone grinding alone on the deviated side, increased movement of the distal segment of the mandible prevented offset of condylar torque, indicating that additional DSPBO or plate bending is required. Notably, lateral displacement occurred on the deviated side in Group II indicating that lateral condylar displacement increases after SSRO.

For condyle rotation on the deviated side, Group I $\left(-7.11^{\circ} \pm\right.$ $\left.6.87^{\circ}\right)$ treated with IVRO showed outward rotation, and Group II $\left(6.45^{\circ} \pm 3.78^{\circ}\right)$ treated with SSRO showed inward rotation. This finding can be attributed to the nature of IVRO; the proximal segment overlaps the buccal area of the distal segment and the condyle rotates outward in this process. However, due to the characteristics of SSRO, the operator applies a certain amount of force to align the proximal segment to the distal segment. The condyle shows inward rotation because it is fixed with a plate. This feature is observed when examining the rotational tendency of the non-deviated side condyle using SSRO.

The anteroposterior change did not show a significant difference between the two groups; Group I was $0.87 \pm 1.44$ $\mathrm{mm}$ and Group II was $0.66 \pm 0.90 \mathrm{~mm}$, indicating the deviated side condyle moved forward in both groups. Rotskoff et al. ${ }^{9}$ showed the condyle moved anteriorly immediately after IVRO. Group II condyles that underwent SSRO moved slightly forward, which can be expected because the proximal segment was fixed while being moved slightly forward from its original position when the surgeon attached it to the distal segment.

As mentioned above, changes in the condylar position tended to differ depending on the surgical method. However, a distinct difference in the postoperative TMD symptoms between the groups was not observed, and the symptoms improved, as shown in Table 2. Group II condyles that underwent BSSRO showed a greater amount of condylar position change than Group I, with improved TMD symptoms, probably because some bony interferences were eliminated by grinding to minimize condylar torque. Furthermore, physical therapy following surgery and the resolution of facial asym- metry resulted in improved masticatory muscle activity and resolution of several TMD symptoms. However, these results do not indicate the change in condylar location is independent of the occurrence and exacerbation of TMD symptoms. A total of 18 patients were analyzed in this study, limiting our ability to generalize the improvement in TMD symptoms. Further studies in which the 3D movement of the condyle, including the sagittal and coronal aspects, is investigated using a larger cohort are needed for a more accurate evaluation.

\section{Conclusion}

Evaluation of changes in condylar position using 3D CT superimposition showed the condyle on the deviated side slightly moved after IVRO (Group I), with a tendency of outward rotation. The deviated-side condyle in patients who underwent BSSRO (Group II) showed lateral movement and inward rotation. The condylar position change was distinctly different between the two groups. IVRO on the deviated side successfully minimized condylar torque when a large amount of mandibular rotation was required to match the menton to the midline of the face.

The correlation between how much the condyle changes from its original position after surgery, and whether TMD worsens and develops, should be investigated in future studies. The obtained results can help surgeons and orthodontists predict and manage the changes in TMD symptoms after surgery.

\section{ORCID}

Jun Park, https://orcid.org/0000-0002-0790-4884

Ki-Eun Hong, https://orcid.org/0000-0003-3358-8325

Ji-Eon Yun, https://orcid.org/0000-0002-4928-7327

Eun-Sup Shin, https://orcid.org/0000-0002-7654-2418

Chul-Hoon Kim, https://orcid.org/0000-0002-2719-1922

Bok-Joo Kim, https://orcid.org/0000-0002-7482-8738

Jung-Han Kim, https://orcid.org/0000-0002-3469-6136

\section{Authors' Contributions}

J.P. and J.H.K. participated in conception and design of study. J.P. and J.H.K. participated in acquisition of data. J.P., K.E.H., E.S.S., and J.E.Y. participated in analysis and interpretation of data. J.P. and J.H.K. participated in drafting the manuscript. C.H.K., B.J.K., and J.H.K. participated in revising manuscript critically for important intellectual content. 
J.P. and J.H.K. participated in approval of the version of the manuscript to be published.

\section{Acknowledgements}

This work was supported by the Dong-A University research fund.

\section{Ethics Approval and Consent to Participate}

This study design complied with and was approved by the Ethics Committee of Dong-A University (IRB No. 2021094). All of the participants signed an informed consent form.

\section{Consent for Publishing Photographs}

Written informed consent was obtained from the patients for publication of this article and accompanying images.

\section{Conflict of Interest}

No potential conflict of interest relevant to this article was reported.

\section{References}

1. Ellis E 3rd. A method to passively align the sagittal ramus osteotomy segments. J Oral Maxillofac Surg 2007;65:2125-30. https:// doi.org/10.1016/j.joms.2007.02.005

2. Ghali GE, Sikes JW Jr. Intraoral vertical ramus osteotomy as the preferred treatment for mandibular prognathism. J Oral Maxillofac Surg 2000;58:313-5. https://doi.org/10.1016/s02782391(00)90063-6

3. Trauner R, Obwegeser H. The surgical correction of mandibular prognathism and retrognathia with consideration of genioplasty. II. Operating methods for microgenia and distoclusion. Oral Surg Oral Med Oral Pathol 1957;10:899-909. https://doi.org/10.1016/s00304220(57)80041-3

4. Spiessl B. [Osteosynthesis in sagittal osteotomy using the Obwegeser-Dal Pont method]. Fortschr Kiefer Gesichtschir 1974;18:145-8. German.

5. Watzke IM, Heinrich A. The impact of bilateral sagittal split osteotomy on mandibular width and morphology. J Oral Maxillofac Surg 2002;60:502-4; discussion 505. https://doi.org/10.1053/ joms.2002.31845

6. Proffit RP, White PJ. Surgical-orthodontics treatment. St. Louis: Mosby; 1990

7. Steinhäuser EW. Historical development of orthognathic surgery. J Craniomaxillofac Surg 1996;24:195-204. https://doi.org/10.1016/ s1010-5182(96)80002-3

8. Jung HD, Jung YS, Park HS. The chronologic prevalence of temporomandibular joint disorders associated with bilateral intraoral vertical ramus osteotomy. J Oral Maxillofac Surg 2009;67:797803. https://doi.org/10.1016/j.joms.2008.11.003
9. Rotskoff KS, Herbosa EG, Nickels B. Correction of condylar displacement following intraoral vertical ramus osteotomy. J Oral Maxillofac Surg 1991;49:366-72; discussion 373-4. https://doi. org/10.1016/0278-2391(91)90372-s

10. Onizawa K, Schmelzeisen R, Vogt S. Alteration of temporomandibular joint symptoms after orthognathic surgery: comparison with healthy volunteers. J Oral Maxillofac Surg 1995;53:117-21; discussion 122-3. https://doi.org/10.1016/0278-2391(95)90383-6

11. Wolford LM, Reiche-Fischel O, Mehra P. Changes in temporomandibular joint dysfunction after orthognathic surgery. J Oral Maxillofac Surg 2003;61:655-60; discussion 661. https://doi.org/10.1053/ joms.2003.50131

12. Lee JH, Park TJ, Jeon JH. Unilateral intraoral vertical ramus osteotomy and sagittal split ramus osteotomy for the treatment of asymmetric mandibles. J Korean Assoc Oral Maxillofac Surg 2015;41:102-8. https://doi.org/10.5125/jkaoms.2015.41.2.102

13. Panula K, Finne K, Oikarinen K. Incidence of complications and problems related to orthognathic surgery: a review of 655 patients. J Oral Maxillofac Surg 2001;59:1128-36; discussion 1137. https:// doi.org/10.1053/joms.2001.26704

14. Hwang SJ, Haers PE, Zimmermann A, Oechslin C, Seifert B, Sailer HF. Surgical risk factors for condylar resorption after orthognathic surgery. Oral Surg Oral Med Oral Pathol Oral Radiol Endod 2000;89:542-52. https://doi.org/10.1067/moe.2000.105239

15. Dujoncquoy JP, Ferri J, Raoul G, Kleinheinz J. Temporomandibular joint dysfunction and orthognathic surgery: a retrospective study. Head Face Med 2010;6:27. https://doi.org/10.1186/1746160X-6-27

16. Al-Moraissi EA, Wolford LM, Perez D, Laskin DM, Ellis E 3rd Does orthognathic surgery cause or cure temporomandibular disorders? A systematic review and meta-analysis. J Oral Maxillofac Surg 2017;75:1835-47. https://doi.org/10.1016/j.joms.2017.03.029

17. Jung HD, Kim SY, Park HS, Jung YS. Orthognathic surgery and temporomandibular joint symptoms. Maxillofac Plast Reconstr Surg 2015;37:14. https://doi.org/10.1186/s40902-015-0014-4

18. Kang MG, Yun KI, Kim CH, Park JU. Postoperative condylar position by sagittal split ramus osteotomy with and without bone graft. J Oral Maxillofac Surg 2010;68:2058-64. https://doi.org/10.1016/ j.joms.2009.12.015

19. Ueki K, Degerliyurt K, Hashiba Y, Marukawa K, Nakagawa K, Yamamoto E. Horizontal changes in the condylar head after sagittal split ramus osteotomy with bent plate fixation. Oral Surg Oral Med Oral Pathol Oral Radiol Endod 2008;106:656-61. https://doi. org $/ 10.1016 /$ j.tripleo.2008.03.016

20. Yang HJ, Hwang SJ. Change in condylar position in posterior bending osteotomy minimizing condylar torque in BSSRO for facial asymmetry. J Craniomaxillofac Surg 2014;42:325-32. https:/ doi.org/10.1016/j.jcms.2013.05.021

21. Epker BN, Stella JP, Fish LC. Dentofacial deformities: integrated orthodontic and surgical correction. 2nd ed. St. Louis: Mosby; 1999.

22. Naran S, Steinbacher DM, Taylor JA. Current concepts in orthognathic surgery. Plast Reconstr Surg 2018;141:925e-36e. https://doi. org/10.1097/PRS.0000000000004438

How to cite this article: Park J, Hong KE, Yun JE, Shin ES, Kim $\mathrm{CH}$, Kim BJ, et al. Positional changes of the mandibular condyle in unilateral sagittal split ramus osteotomy combined with intraoral vertical ramus osteotomy for asymmetric class III malocclusion. J Korean Assoc Oral Maxillofac Surg 2021;47:373-381. https://doi. org/10.5125/jkaoms.2021.47.5.373 